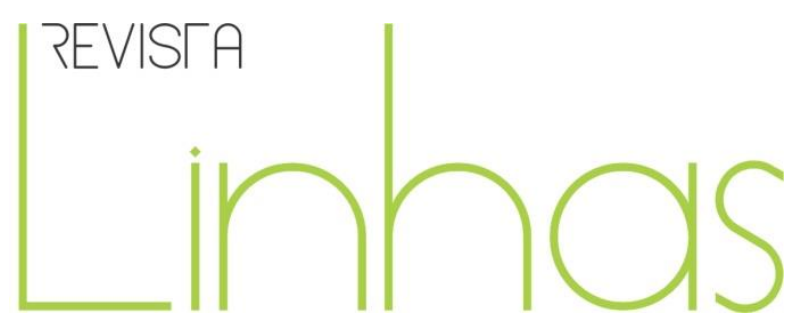

\title{
Das histórias de amores (im)possíveis: Inês, de Roger Mello e Mariana Massarani
}

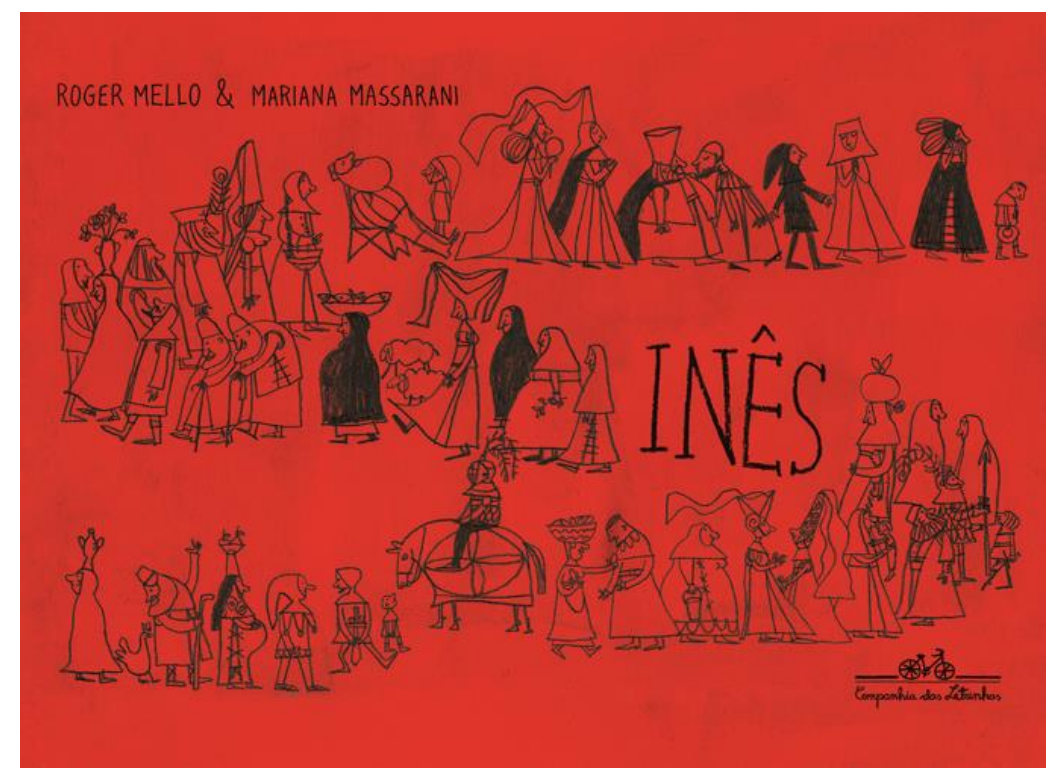

MELLO, Roger. Inês. Ilustração de Mariana Massarani. São Paulo: Cia. das Letrinhas, 2015.

\section{Maria Laura Pozzobon Spengler}

Universidade Federal de Santa Catarina - UFSC - Brasil

lolyzinha@hotmail.com

\section{Eliana Santana Dias Debus}

Universidade Federal de Santa Catarina - UFSC - Brasil

elianedebus@hotmail.com

\section{Para citar esta resenha:}

SPLENGER, Maria Laura Pozzobon; DEBUS, Eliana Santana Dias. Resenha do livro "Inês". Revista Linhas.

Florianópolis, v. 18, n. 37, p. 313-317, maio/ago. 2017.

DOI: $10.5965 / 1984723818372017313$

http://dx.doi.org/10.5965/1984723818372017313 
Os livros literários contemporâneos para crianças se destacam, especialmente, pela composição que surge a partir do conjunto entre o texto escrito, as ilustrações e o projeto gráfico, e, dentro deste, o conjunto dos paratextos, que muito além de funcionar como uma porta de entrada para o texto narrativo, ampliam sua significação, quando auxiliam o leitor a introduzir-se na leitura, facilitando as primeiras impressões sobre o conteúdo do livro, funcionando "como uma porta de entrada, de transição e de transacção com a leitura [...]”' (LLUCH, 2006, p. 217), e trazendo a ele novos elementos fundamentais que ampliam a significação da narrativa do livro (NIKOLAJEVA; SCOTT, 2011).

Os paratextos são parte integrante da construção material do livro e podemos destacar, na esteira de Nikolajeva e Scott (2011), o formato do livro, capas e títulos, as guardas, o frontispício - conhecido como folha de rosto - e a quarta capa. As estudiosas afirmam que o formato do livro nunca é acidental e, portanto, participa da "totalidade estética do livro" (NIKOLAJEVA; SCOTT, 2011, p. 307), isto é, a escolha por um formato horizontal, quadrado ou vertical servem para retratar movimento e espaço da narrativa, e a escolha por qualquer um deles afeta a apreciação e leitura do livro. Já as capas dos livros ilustrados, como se encontram na contemporaneidade, apresentam uma imagem, que pode estar presente no miolo do livro, ou alguma imagem original, fornecendo informações sobre o enredo da narrativa e seus personagens; é um convite explícito ao leitor: abra-me e devora-me.

A folha de rosto - ou frontispício -, traz habitualmente o título do livro, nome do(s) autor(es) e também o nome da editora e dedicatórias. Pode acontecer de um livro ter mais de uma folha de rosto, ou várias delas, cada uma com uma imagem simbólica relacionadas ao enredo, diferente das anteriores. A quarta capa, ou contracapa, é a parte oposta à capa. Normalmente continua a imagem da capa e são usadas para apresentar um breve resumo do enredo ou apresentar o(s) autor(es).

Em Inês, de Roger Mello (2015), o leitor é prontamente convidado a entrar na narrativa, quando se depara, junto do título escrito à mão em fundo vermelho, a uma fila enorme de pessoas com as mais variadas características físicas, mulheres, homens e 
crianças, e alguns animais. A fila que preenche o espaço da capa e quarta capa se amplia até as folhas de guarda. Convidado a fazer parte dessa fila, o leitor adentra a narrativa.

As guardas dos livros contemporâneos foram descobertas pelos autores/editores/designers como paratextos que contribuem para a construção da história, servindo como uma cena introdutória à narração, ou acrescentando pistas sobre a história que será contada, estimulando, assim, a imaginação do leitor, influenciando na sua interpretação. No caso do livro em questão, é nas guardas (inicial e final) que o leitor descobre onde culmina a fila que ocupa o espaço da capa e quarta capa: no cumprimento à rainha que acaba de ser coroada.

O livro Inês é constituído de 52 páginas e produzido em capa dura; tem formato retangular; duplica o tamanho de cada uma das imagens quando aberto, alcançando um pouco mais de meio metro de largura. As imagens ocupam o conjunto de páginas duplas, ainda que sejam duas ilustrações dividindo o espaço, são complementares uma à outra. Algumas delas margeadas por desenhos florais, que lembram antigas iluminuras.

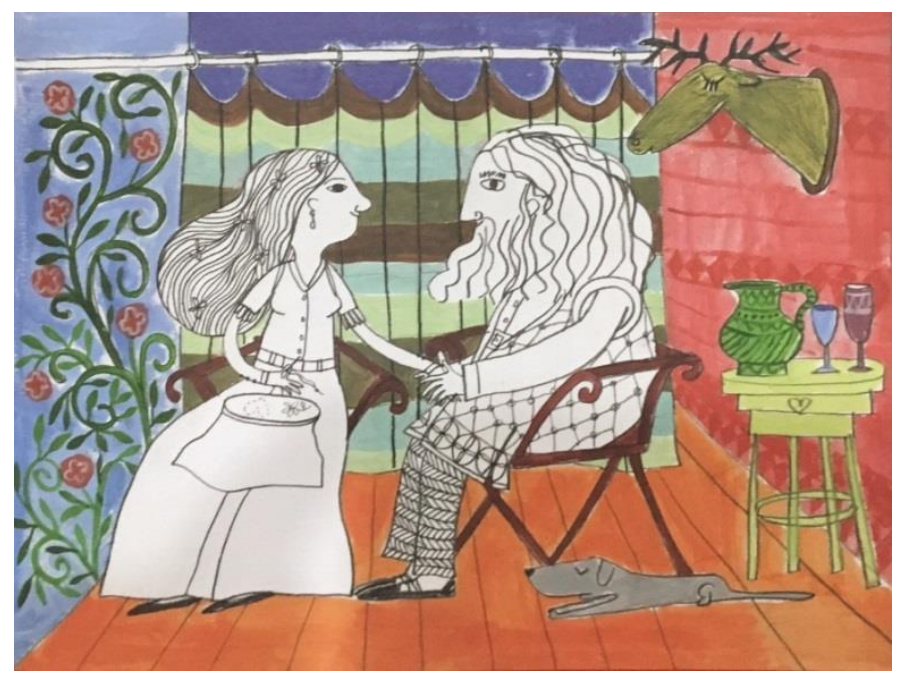

Ilustração da página 30 do livro Inês Fonte: Acervo pessoal.

A narrativa, alicerçada em uma linguagem feérica, é narrada em primeira pessoa por Beatriz, a filha de Pedro, o príncipe, e Inês, a ama da princesa prometida ao príncipe, mas que vira rainha em algum momento da história portuguesa. É Beatriz, filha do amor proibido, que tece com os fios da delicadeza e da singeleza da infância essa história encharcada de boniteza. 
É pelo olhar das personagens que o leitor se insere dramática e profundamente na narrativa; é por esses olhares laterais e incisivos que o leitor se sente cúmplice da voz de Beatriz, sente-se próximo dela, dividindo com ela os sentimentos que, invisíveis à escrita e à ilustração, preenchem os vazios que constroem os sentidos da história.

O vermelho vivo da capa, abrindo a narrativa, inquieta e garante ao livro a ambivalência da história: o amor e o destino cruel representado pelo sangue da rainha morta, o vermelho que convida ao amor, e o vermelho que o proíbe. A imagem desenhada do coração, símbolo do amor, é mostrado ao leitor, também de forma ambivalente, pois está em sua forma científica, aquela apresentada nos desenhos médicos, o mesmo coração que representa o amor, também representa a finitude da vida.

Inês é o primeiro livro depois de Roger Mello (2015) ter sido agraciado com o prêmio internacional Hans Christian Andersen, em 2014, considerado o Prêmio Nobel que os escritores para a infância e juventude recebem pelo conjunto de sua obra. O livro, lançado no ano de 2015, recebeu em 2016 os maiores prêmios destinados à literatura para a infância brasileira. Foi escolhido como melhor livro para crianças pela Fundação Nacional do livro Infantil e Juvenil, e escolhido como melhor livro para crianças pela curadoria do Prêmio Jabuti.

Roger Mello e Mariana Massarani, mais uma vez, dividem a autoria do livro, ele na escrita, ela nas ilustrações, atualizando sua marca registrada de estilo: os traços simples na cor preta em fundos coloridos. Juntos reafirmam a amizade cúmplice que culmina na parceria criativa já experimentada em outros momentos. O conjunto do trabalho de ambos garante a literariedade da narrativa; ilustração e texto escrito complementam-se, somam-se, engendram-se, de tal maneira que um não sobreviveria sem o outro.

A narrativa traz à tona a história de amor de Dom Pedro I e Inês de Castro, que com ele teve quatro filhos fora do casamento e é assassinada em 1355, a mando de Dom Afonso IV. Após a sua morte, Inês é trazida por Dom Pedro I para Portugal, oficializando o casamento com a morta. Daí o ditado tantas vezes dito quando algo não acontece a 
contento ou é dado por acabado: “Inês é morta". Essas informações deslizam pelo texto de forma delicada e sutil, não o caracterizando como livro informativo.

Entre o conjunto de paratextos que completam a obra, um deles é particularmente importante, um pequeno texto, de autoria da historiadora Lilia Moritz Schwarcs, contextualizando historicamente a verdadeira história da protagonista Inês, a ama espanhola que se apaixona pelo príncipe e, correspondida, dá início a uma história de amor proibida, até ser assassinada a mando do rei.

\section{Referências}

LLUCH, Gemma. Para uma selecção adequada do livro: das capas ao estilo da literatura comercial. In: AZEVEDO, Fernando (Org.). Língua materna e literatura infantil: elementos nucleares para professores do Ensino Básico. Lisboa: Lidel, 2006. p. 215-230.

NIKOLAJEVA, Maria; SCOTT, Carole. Livro Ilustrado: palavras e imagens. Tradução de Cid Knipel. São Paulo: Cosac Naify, 2011. 